\title{
ESTUDO DO EMPREENDEDORISMO SOB A ÓTICA DO DESENVOLVIMENTO SUSTENTÁVEL
}

DOI: 1014211/Rege33222

Artigo recebido em:30/11/2014 Artigo aprovado em:18/09/2015

Thálita Anny Estefanuto Orsiolli - Universidade Federal do Paraná - UFPR ${ }^{1}$ Farley Simon Mendes Nobre - Universidade Federal do Paraná - UFPR ${ }^{2}$

Resumo: Inúmeras discussões sobre o desenvolvimento sustentável têm estimulado os diversos atores na sociedade e, em especial, as empresas, a repensarem suas estratégias a fim de contribuir não somente para o crescimento econômico, mas também na criação de valores socioambientais e, sobretudo, garantir que as necessidades das gerações atuais possam também ser atendidas pelas futuras gerações. Diante disso, o empreendedorismo sustentável pode ser compreendido como uma extensão do empreendedorismo tradicional (econômico), ao envolver em sua perspectiva as dimensões econômica, social e ambiental. Sob esse contexto, este artigo propõe levantar critérios do empreendedorismo sustentável e associá-los às dimensões do desenvolvimento sustentável, contribuindo para a discussão e melhor compreensão sobre como o empreendedorismo corrobora para um desenvolvimento que envolva dimensões econômica, social e ambiental. O Sistema Mandalla de Produção Familiar Rural (SMPFR) é utilizado nesta pesquisa como forma de demonstrar a associação entre os dois construtos investigados. Desta forma, utiliza-se de pesquisa bibliográfica, caracterizada como exploratória e qualitativa. Os resultados corroboram com a premissa de que o empreendedorismo sustentável contribui para o desenvolvimento sustentável à medida que proporciona condições necessárias para a criação de valores econômicos, sociais e ambientais, de maneira conjunta, por meio de suas estratégias de negócios.

Palavras-chave: Empreendedorismo Sustentável; Desenvolvimento Sustentável; Sistema Mandalla de Produção Familiar Rural.

\section{ENTREPRENEURSHIP FROM SUSTAINABLE DEVELOPMENT PERSPECTIVE}

Abstract: Discussions about sustainable development have encouraged the various actors in society and, in particular, companies to rethink their strategies in order to contribute not only to economic growth, but also to create social and environmental values, and to ensure that the needs of current generations can also be met by future

\footnotetext{
${ }^{1}$ Endereço: Avenida Prefeito Lothario Meissner, 632, $2^{\circ}$ andar, Jardim Botânico, Curitiba - PR, CEP: 80210-170. E-mail: thalitanny@gmail.com

2 E-mail: fsmnobre@gmail.com
}

ORSIOLLI, T. A. E.; NOBRE, F. S. Estudo do empreendedorismo sob a ótica do desenvolvimento sustentável. Revista de Empreendedorismo e Gestão de Pequenas Empresas, v.4, n.3, 2015. 
ones. Therefore, sustainable entrepreneurship can be understood as an extension of traditional entrepreneurship (economic) to engage in their perspective economic, social and environmental dimensions. In this context, this article aims to raise aspects of the sustainable entrepreneurship and link them to the dimensions of sustainable development, contributing to discussion and to a better understanding of how entrepreneurship supports a development that involves economic, social and environmental dimensions. The Mandalla System for Rural Family Production (SMPFR) is used in this research as a way to demonstrate the association between the two investigated constructs. In this way, it was used a bibliographic search, characterized as exploratory and qualitative. Results support the premise that sustainable entrepreneurship contributes to sustainable development as it provides necessary conditions for creation of economic, social and environmental values, jointly, through their business strategies.

Keywords: Sustainable Entrepreneurship; Sustainable Development; Mandalla Rural Family Production System.

\section{Introdução}

É de verificar-se que as discussões envolvendo os impactos ambientais decorrentes do desenvolvimento industrial e econômico se intensificaram a partir da década de 1960, com movimentos que aprofundaram discussões sobre como os processos de produção e consumo têm afetado o meio ambiente com o qual relacionam-se os diversos setores da sociedade.

Esses movimentos ganharam maior projeção mundial com a participação da Organização das Nações Unidas (ONU) e a criação da Comissão Mundial do Meio Ambiente para o Desenvolvimento (CMMAD) em 1983. A partir disso, foram estabelecidas diretrizes, políticas e acordos com os países envolvidos a fim de reduzir os impactos ambientais e sociais (SACHS, 1997; ELKINGTON, 2012; CMMAD, 1991).

Na publicação do Relatório Nosso Futuro Comum, também nomeado como relatório de Brundtland, em 1987, resultado da CMMAD, definiu-se desenvolvimento sustentável como "aquele que atende as necessidades do presente sem comprometer a capacidade das futuras gerações atenderem as suas próprias necessidades" (CMMAD, 1991, p. 46). Tal relatório promulga o conceito de desenvolvimento sustentável, destacando-o como forma de desenvolvimento e progresso, relacionado aos impactos ambientais e sociais, pois fundamenta que os recursos podem ser usados de forma moderada e planejada, estendendo sua 
duração e ampliando oportunidades para corresponder às necessidades atuais e futuras dos seres humanos e da sociedade como um todo (CMMAD, 1991; HALL; DANEKE; LENOX, 2010).

Desta forma, a proposta do desenvolvimento sustentável passa a orientar nações, governos e organizações a buscarem soluções para problemas socioambientais causados pelo progresso, modernidade e globalização, sendo considerado um dos movimentos mais relevantes deste início de século e milênio (BARBIERI et al., 2010). Com isso, as organizações passam a notar e, por consequência, incorporar as iniciativas advindas desse fenômeno às suas estratégias, uma vez que o ambiente empresarial é percebido como agente social que participa da sociedade e torna-se responsável tanto por suas próprias atitudes, como de seus fornecedores, clientes e comunidade onde atuam (ALIGLERI; ALIGRERI; KRUGLIANSKAS, 2009).

Para agir de acordo com as expectativas exigidas pelo mercado e pela sociedade, bem como reduzir impactos ambientais e sociais, as empresas procuram modificar seus métodos organizacionais e repensar soluções que poderiam vir a ser adotadas em favor do desenvolvimento sustentável (ALIGLERI; ALIGRERI; KRUGLIANSKAS, 2009). Barbieri et al. (2010) e Gimenez (2012) destacam que esse processo de mudança nas empresas, proporcionado pelo desenvolvimento sustentável, pode criar oportunidades inovadoras de negócios e gerar vantagem competitiva.

Cumpre observar que a preocupação com a degradação de sistemas ecológicos e sociais demanda das empresas a criação de novos modelos de gestão e de produção que respondam não somente às novas condições de mercado, mas também que respeitem os limites da natureza e as necessidades de classes sociais menos favorecidas e das futuras gerações (ALIGLERI; ALIGRERI; KRUGLIANSKAS, 2009). Esta preocupação contribuiu para que pesquisadores explorassem maneiras de como o empreendedorismo poderia ser estendido para contemplar estratégias que pudessem ser orientadas de acordo com princípios do desenvolvimento sustentável (PARRISH, 2010).

Assim, "o campo do empreendedorismo se interessa cada vez mais pelo desenvolvimento sustentável" (RAUFFLET; BRES; FILION, 2014, p. 3) e passa a 
incorporar os aspectos sociais e ambientais, atuando como agente que corrobora para este tipo de desenvolvimento, bem como proporcionando uma visão holística de criação de valor (PACHECO; DEAN; PAYNE, 2010; COHEN; SMITH; MITCHEL, 2008).

Nessa linha, a gestão voltada para o desenvolvimento sustentável pode ser verificada por meio do empreendedorismo sustentável (COHEN; WINN, 2007; SCHALTEGGER; WAGNER, 2011). Este abrange as dimensões econômica, social e ambiental ao mesmo tempo, e a partir de inovações, busca contribuir para o desenvolvimento sustentável da própria organização, bem como para o mercado e sociedade como um todo (SCHALTEGGER; WAGNER, 2011).

Deste modo, é possível notar que essa forma emergente de empreendedorismo surge como uma maneira de demonstrar uma nova percepção dos empreendedores quanto ao uso de recursos ambientais e criação de valor para a sociedade (MAIJD; KOE, 2012; BOSZCZOWSKI; TEIXEIRA, 2012; HALL; DANEK; LENOX, 2010).

Entende-se, nesta pesquisa, que existem distintas estratégias de sustentabilidade que contribuem para um desenvolvimento sustentável (NOBRE; RIBEIRO, 2013; NOBRE; WALKER; HARRIS, 2012). Contudo, embora algumas relações entre estratégias de sustentabilidade e dimensões do desenvolvimento sustentável sejam aparentemente tautológicas, deve-se ressaltar a importância de descrever como essas relações estão associadas, ou se formam, e compreender quais estratégias estão associadas a cada uma das dimensões.

Sendo assim, é essencial definir os elementos constituintes de ambos os construtos, a partir de suas particularidades, a fim de contribuir para o entendimento dos pressupostos que associam o empreendedorismo ao desenvolvimento sustentável.

Neste sentido, o presente artigo propõe levantar critérios do empreendedorismo sustentável e associá-los às dimensões do desenvolvimento sustentável, contribuindo para a discussão e melhor compreensão sobre como o empreendedorismo corrobora para um desenvolvimento que envolva dimensões econômica, social e ambiental. 
O presente estudo faz uso do Sistema Mandalla de Produção Familiar Rural (SMPFR) como forma de demonstrar a associação entre os construtos empreendedorismo sustentável e dimensões do desenvolvimento sustentável. Para tanto, utiliza-se de pesquisa bibliográfica, caracterizada como exploratória e qualitativa.

Em função de seus objetivos, este artigo foi estruturado da seguinte forma: (i) introdução; (ii) procedimentos metodológicos; (iii) referencial teórico sobre o empreendedorismo sustentável e o desenvolvimento sustentável; (iv) associação entre critérios do empreendedorismo sustentável e dimensões do desenvolvimento sustentável; (v) estudo do Sistema Mandalla de Produção Familiar Rural (SMPFR); (vi) discussão e considerações finais.

\section{Procedimentos metodológicos}

Este estudo possui caráter exploratório por buscar informações acerca de um objeto de pesquisa que possui pouca ou nenhuma informação no contexto a ser investigado (COLLIS; HUSSEY, 2005). Esta questão se justifica pelo fato de o campo do empreendedorismo sustentável ser considerado emergente (BOSZCZOWSKI; TEIXEIRA, 2012).

Embora existam pesquisas sobre este tema, ainda faltam estudos que aprofundem as discussões a respeito do desenvolvimento sustentável e empreendedorismo (HALL; DANEKE; LENOX, 2010). Deste modo, evidenciou-se falta de pesquisas que levantassem critérios da literatura e explorassem a associação entre os critérios do empreendedorismo sustentável e as dimensões do desenvolvimento sustentável.

Para isso, utilizou-se a pesquisa bibliográfica como estratégia de pesquisa, com o propósito de "conhecer, analisar e explicar contribuições sobre determinado assunto, tema ou problema", baseando-se em "referências publicadas em livros, periódicos, enciclopédias, dicionários, jornais, sites, CDs, anais de congresso, etc." (MARTINS; THEÓPHILO, 2007, p. 54). A escolha por esta estratégia se deu pelo fato de buscar, na plataforma teórica, aprofundar discussões a respeito do objeto em 
análise nesta pesquisa (MARTINS; THEÓPHILO, 2007; DEZIN; LINCOLN, 2006; CERVO; BERVIAN, 2002).

Nesse sentido, este estudo investigou em livros, periódicos classificados em Qualis Capes A1 a B3 e anais de congresso, referências que fundamentassem os critérios relacionados ao empreendedorismo sustentável e ao desenvolvimento sustentável. Para o Sistema Mandalla de Produção Familiar Rural (SMPFR), também estudado por meio de pesquisa bibliográfica, foram empregados os mesmos critérios de busca mencionados anteriormente.

Diante disso, utilizou-se da análise de conteúdo como meio para analisar os dados obtidos, uma vez que este procedimento é utilizado para analisar o material textual, independente de sua origem, compreendendo desde materiais de mídia até dados de entrevista (FLICK, 2004).

Assim, para analisar os textos examinados neste estudo, foram utilizadas as três fases delineadas por Bardin (1977): i) pré-análise - definição dos critérios do empreendedorismo sustentável e desenvolvimento sustentável extraídos da literatura; ii) exploração do material - a partir da definição, procurou-se relacionar os critérios destes dois construtos, a fim de entender como alguns desafios do desenvolvimento sustentável podem ser minimizados por meio de ações empreendedoras.

De maneira semelhante, utilizou-se o SMPFR como forma de compreender como estes dois construtos se inter-relacionam; iii) tratamento dos resultados - após a obtenção dos critérios do empreendedorismo e desenvolvimento sustentável, buscou-se no SMPFR dados que pudessem ser associados às dimensões econômica, ambiental e social.

Os códigos utilizados na análise foram definidos em categorias relacionadas às dimensões econômica, ambiental e social, adequando aos critérios definidos para o empreendedorismo sustentável e desenvolvimento sustentável (quadro 2). Após isso, foram destacadas as características constituintes do SMPFR, separando-as de acordo com as dimensões estabelecidas (quadro 3).

Mediante as questões apresentadas sobre a coleta e análise dos dados, será possível obter a legitimidade e confiabilidade dos dados, uma vez que se 
apresenta uma descrição detalhada dos procedimentos metodológicos e o uso das diversas fontes de dados.

\section{Empreendedorismo sustentável}

Antes de tudo é importante evidenciar que alguns autores associam o empreendedorismo à geração de riqueza e crescimento econômico (GATNER, 1989; VENKATARAMAN, 1997). É certo que o empreendedorismo passou por um processo de mudanças devido à instabilidade mercadológica, proporcionando a incorporação de fatores que se relacionam com a capacidade de inovação em produtos e processos, e, ao mesmo tempo, se preocupem com as questões ambientais e sociais (MAJID; KOE, 2012; BOSZCZOWSKI; TEIXEIRA, 2012).

Para responder a essa perspectiva, os empreendedores passam a ser percebidos como agentes de mudanças, buscando agregar novos métodos (SILVA et al., 2012) a fim de corresponder tanto às expectativas de seus stakeholders (internos e externos) quanto às exigências do mercado, e com isso, criar novas oportunidades de geração de valor para seus empreendimentos (PARRISH, 2008).

Nessa perspectiva, Parrish (2008) aponta que o campo do empreendedorismo é estendido e reinterpretado, com o propósito de demonstrar preocupação além da ideia de desenvolvimento econômico e da produtividade, para abranger fatores que se relacionam ao desenvolvimento sustentável, uma vez que este fenômeno possibilitou à sociedade e às organizações perceberem a maneira pela qual os problemas ecológicos implicavam na economia, no ambiente social e físico, de modo que o desenvolvimento econômico passa a ser integrado às soluções ambientais e sociais (TILLEY; YOUNG, 2009). Assim, é correto dizer que novas formas de empreendedorismo surgem em concordância com os preceitos do desenvolvimento sustentável. Schaltegger e Wagner (2011) evidenciam essa relação a partir dos diferenciados tipos de empreendedorismo orientados ao propósito da sustentabilidade, levando em consideração aspectos como: motivação central, principal objetivo, papel dos objetivos econômicos, papel dos objetivos não 
mercadológicos e desafios do desenvolvimento organizacional, os quais podem ser verificados na tabela 1 .

Tabela 1 - Caracterização dos diferentes tipos de empreendedorismo orientados à sustentabilidade

\begin{tabular}{|c|c|c|c|c|}
\hline & $\begin{array}{l}\text { Eco } \\
\text { empreendedoris } \\
\text { mo }\end{array}$ & $\begin{array}{l}\text { Empreendedorism } \\
\text { o Social }\end{array}$ & $\begin{array}{l}\text { Empreendedorism } \\
\text { o Institucional }\end{array}$ & $\begin{array}{l}\text { Empreendedoris } \\
\text { mo Sustentável }\end{array}$ \\
\hline $\begin{array}{l}\text { Motivação } \\
\text { Principal }\end{array}$ & $\begin{array}{lr}\text { Contribui rara } & \text { pasolver } \\
\text { resos } \\
\text { problemas } \\
\text { ambientais e criar } \\
\text { valor econômico }\end{array}$ & $\begin{array}{l}\text { Contribui } \\
\text { para resolver } \\
\text { problemas } \\
\text { sociais e } \\
\text { criar valor } \\
\text { para a a } \\
\text { sociedade }\end{array}$ & $\begin{array}{l}\text { Contribui para } \\
\text { mudança } \\
\text { regulatória, } \\
\text { social e das } \\
\text { instituições de } \\
\text { mercado }\end{array}$ & $\begin{array}{l}\text { Contribui para } \\
\text { resolver } \\
\text { problemas } \\
\text { ambientais e } \\
\text { sociais através } \\
\text { da realização } \\
\text { de um negócio } \\
\text { de sucesso }\end{array}$ \\
\hline
\end{tabular}

Objetivo Principal
Ganhar dinheiro resolvendo problemas ambientais
Alcançar a meta social e assegurar financiamento para isto

$\begin{array}{ll}\text { Mudar as } & \text { Criar } \\ \text { instituições } & \text { desenvolvimento } \\ \text { como objetivo } & \text { sustentável através } \\ \text { direto } & \text { das atividades } \\ & \text { coorporativas } \\ & \text { empreendedoras }\end{array}$

Papel dos Fins $\quad$ Meios Meios e fins
Objetivos
Econômicos

\begin{tabular}{|c|c|c|c|c|}
\hline $\begin{array}{l}\text { Papel dos } \\
\text { Objetivos não } \\
\text { mercadológic } \\
\text { os }\end{array}$ & $\begin{array}{l}\text { Questões } \\
\text { ambientais como } \\
\text { elementos } \\
\text { centrais } \\
\text { integrados }\end{array}$ & $\begin{array}{l}\text { Objetivos } \\
\text { Sociais como } \\
\text { fins }\end{array}$ & $\begin{array}{l}\text { Mudando as } \\
\text { Instituições como } \\
\text { elementos centrais }\end{array}$ & $\begin{array}{l}\text { Elemento central } \\
\text { integrado para } \\
\text { contribuir para o } \\
\text { desenvolvimento } \\
\text { sustentável }\end{array}$ \\
\hline
\end{tabular}

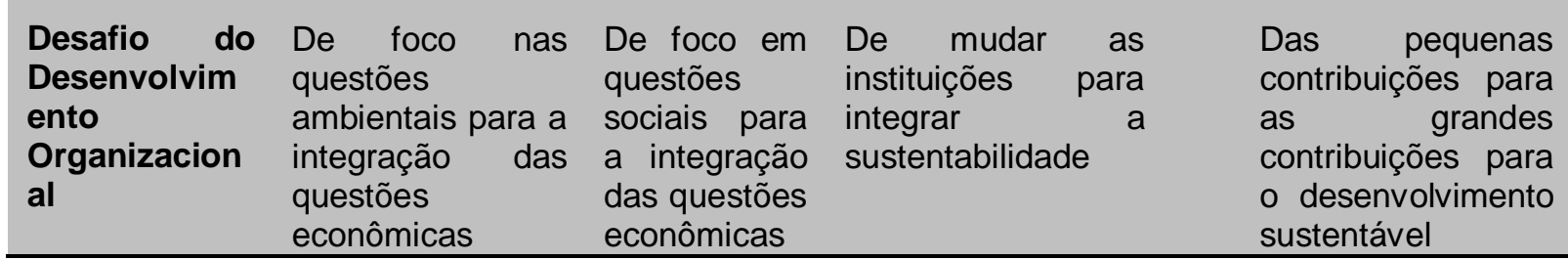

Fonte: Adaptado de Schaltegger e Wagner (2011, p. 224).

Diante disso, é possível destacar o empreendedorismo sustentável como aquele que envolve os preceitos sociais, ambientais e econômicos direcionados ao desenvolvimento sustentável a fim de integrá-los às suas atividades empresariais (produtos, serviços, procedimentos) e com isso gerar valores sustentáveis à sociedade (COHEN; WINN, 2007; SCHALTEGGER; WAGNER, 2011).

ORSIOLLI, T. A. E.; NOBRE, F. S. Estudo do empreendedorismo sob a ótica do desenvolvimento sustentável. Revista de Empreendedorismo e Gestão de Pequenas Empresas, v.4, n.3, 2015. 
O empreendedorismo sustentável é considerado um campo novo de pesquisa (BOSZCZOWSKI; TEIXEIRA, 2012). Isto pode ser observado por meio de diferenciações em sua nomenclatura, pelos termos: sustainable entrepreneurship (GERLACH, 2003; SCHLANGE, 2006; COHEN; WINN, 2007; DEAN; MCMULLEN, 2007; HOCKERTS; WÜSTENHAGEN, 2010; SCHALTEGGER; WAGNER, 2011); sustainability-driven entrepreneurship (PARRISH, 2008; 2010; PARRISH; FOXON, 2009; SCHLANGE, 2009; TILLEY; YOUNG, 2009); sustainability entrepreneurship (O'NEILL; HERSHAUER; GOLDEN, 2009; GIBBS, 2009); e sustainopreneurship (ABRAHAMSSON, 2007).

Esta forma de empreendedorismo surge a partir de estudos relacionados ao desenvolvimento sustentável (SHEPHERD; PATZELT, 2011), com a finalidade de demonstrar que os empreendimentos podem obter lucro e simultaneamente gerar valor ambiental e social (HOCKERTS; WÜSTENHAGEN, 2010). Por ser uma área de estudo em expansão, é possível notar diferentes interpretações sobre seu conceito (BOSZCZOWSKI; TEIXEIRA, 2012, PARRISH, 2008).

Autores como Thompson, Kiefer e York (2011) e Schlange (2006) advogam que o empreendedorismo sustentável se relaciona ao conceito do triple bottom line quando busca equilibrar as questões econômicas, sociais e ambientais, a fim de evidenciar a maneira pela qual os empreendedores buscam relacionar seus objetivos de acordo com as perspectivas do desenvolvimento sustentável. Shepherd e Patzelt (2011) corroboram com o argumento quando ressaltam que esta forma de empreendedorismo se relaciona ao desenvolvimento sustentável na medida em que alguns elementos precisam ser desenvolvidos e outros sustentados.

Para os autores, a natureza (terra, biodiversidade e ecossistemas), as fontes de apoio à vida (ambiente, recursos naturais e serviços dos ecossistemas) e a comunidade (o que contribui para a identidade - cultura, grupos, lugares) devem ser sustentadas. Logo, o ganho econômico, o ganho não econômico para os indivíduos (expectativa de vida, educação, equidade e igualdade de oportunidades) e o ganho não econômico para a sociedade (melhorar a confiança/estrutura social local), devem ser desenvolvidos (SHEPHERD; PATZELT, 2011).

Parrish (2010) enfatiza que o empreendedorismo se diferencia dos demais associados à sustentabilidade, a partir de seu design e estrutura, bem como de seus 
valores incorporados, fato que contribui para compreender o surgimento de modelos de negócio advindos do empreendedorismo sustentável.

O’Neill, Hershauer e Golden (2009) e Schlange (2009) complementam que o empreendedorismo sustentável pode ser observado como uma maneira de corresponder às expectativas de stakeholders (diretos e indiretos), uma vez que relaciona um conjunto específico de questões voltadas para a criação de valor sustentável. Já Abrahamsson (2007) e Choi e Gray (2008) percebem este tipo de empreendedorismo voltado para a obtenção de lucro, porém com suas metas direcionadas à sustentabilidade.

Cohen e Winn (2007) e Dean e McMullen (2007) argumentam que essa forma de empreendedorismo surge a partir de oportunidades proporcionadas pelas falhas de mercado advindas das transformações econômicas, as quais contribuem para que novos modelos de negócios busquem alternativas inovadoras de se desenvolverem economicamente e minimizar os problemas ambientais e sociais (BOSZCZOWSKI; TEIXEIRA, 2012).

O empreendedorismo sustentável também pode ser compreendido por um processo em que os gestores, em primeiro momento, examinam como as oportunidades para trazer à existência futuros bens e serviços são descobertas, criadas e podem vir a ser exploradas, bem como, quais consequências econômicas, psicológicas, sociais e ambientais poderão ser geradas (COHEN; WINN, 2007).

O empreendedorismo sustentável pode ser observado como uma área inovadora, orientada para o mercado e para a criação de valor econômico e social por meio de transformações ambientalmente e socialmente benéficas. Com isso, pode-se afirmar que este tipo de empreendedorismo diverge de muitos pontos de vista do empreendedorismo convencional, pois aumenta o objetivo da influência empresarial para além do sucesso de mercado, a fim de iniciar a mudança social e mudanças nas condições de mercado e regulamentações (SCALTEGGER; WAGNER, 2011).

Young e Tilley (2006) e Tilley e Young (2009) apontam que o empreendedorismo sustentável é uma forma inovadora de negócio que se constitui a partir da incorporação das três dimensões que compõem o desenvolvimento sustentável, diferente do empreendedorismo econômico, social e ambiental. Para os 
autores, esta forma de empreendedorismo direcionado à sustentabilidade une os elementos sustentáveis que direcionam o empreendedor à atividade empresarial desempenhada.

Diante disso, Young e Tilley (2006) sugerem um modelo, desenvolvido a partir da concepção de Dillick e Hockerts (2002), voltado para o empreendimento direcionado aos princípios do desenvolvimento sustentável. Segundo os autores, para que a empresa seja considerada como um caso de empreendedorismo sustentável, é necessário que envolva os doze elementos para que possa evidenciar a relação entre eles (figura 1 ):



Figura 1 - Modelo de empreendedorismo sustentável Fonte: Young e Tilley (2006, p. 410). Tradução livre.

Young e Tilley (2006) explicam que o modelo relaciona estes dozes critérios, os quais também abrangem os três tipos de empreendedorismo, demonstrando os elementos que compõem cada um. Como se observa, os três juntos constituem o empreendedorismo sustentável.

Os autores apontam que a relação entre os tipos de empreendedorismo ocorrem da seguinte forma: 
i) Entre o empreendedorismo econômico e sustentável: envolve equidade econômica (distribuir riqueza entre as gerações presentes e futuras) e equidade entre gerações (bem-estar econômico a partir das decisões e operações empresariais);

ii) Entre o empreendedorismo ambiental e sustentável: compreende a estabilidade ambiental (ações que restaurem e evitem a degradação do ecossistema) e estabilidade ambiental a longo prazo (decisões e operações ambientais empresariais);

iii) Entre o empreendedorismo social e sustentável: é relacionado à responsabilidade social (empresas e indivíduos possuem responsabilidade sobre qualquer impacto que incide sob as gerações futuras) e futuro (bemestar social advindos das decisões e operações empresariais).

A partir do modelo de Young e Tilley (2006), é possível inferir que os empreendimentos, dependendo do tipo de empreendedorismo, podem variar numa escala entre "não sustentáveis, parcialmente sustentáveis e sustentáveis", de modo que poderiam ser segmentados nas seguintes categorias ou grupos: Grupo 1 (empreendimentos que não satisfazem os critérios do empreendedorismo sustentável); Grupo 2 (empreendimentos que satisfazem parcialmente os critérios do empreendedorismo sustentável); e Grupo 3 (empreendimentos que satisfazem os critérios do empreendedorismo sustentável).

Importante notar que as atividades desempenhadas pelo empreendedorismo sustentável se diferenciam das demais formas de empreendedorismo ao mesmo tempo em que se relacionam, pois o imperativo sustentável é adequado ao objetivo de criar novos padrões de produção e consumo que considerem os aspectos ambientais e sociais, para assim, possibilitar mudanças nas condições e regulamentações de mercado e, sobretudo, no bem-estar da sociedade (YOUNG; TILLEY, 2006; SCHALTEGGER; WAGNER, 2011). 


\section{Desenvolvimento sustentável}

A princípio, a noção de desenvolvimento sustentável surgiu a partir da temática do crescimento econômico associada ao problema da degradação ambiental, a fim de relacionar os comportamentos humanos, econômicos e sociais às alterações ocorridas no ambiente natural e territorial (país, região) (VEIGA, 2005).

É primordial observar que a retomada do desenvolvimento é condição necessária para reduzir problemas como a pobreza, desigualdade social, crescimento populacional, degradação ambiental, entre outros (CMMAD, 1991; SACHS, 2008).

De acordo com a definição do Relatório de Brundtland, também denominado "Nosso Futuro Comum", o desenvolvimento sustentável compreende um processo de mudança que direciona investimentos institucionais e a sociedade para utilizarem recursos de modo a responder as necessidades atuais e futuras de todos os seres humanos (CMMAD, 1991). Assim, pode-se complementar que:

O conceito de desenvolvimento sustentável deve ser visto como uma alternativa ao conceito de crescimento econômico, o qual está associado a crescimento material, quantitativo da economia. Isso não quer dizer que, como resultado de um desenvolvimento sustentável, o crescimento econômico deva ser totalmente abandonado. Admitindo-se, antes, que a natureza é a base necessária e indispensável da economia moderna, bem como das vidas das gerações presentes e futuras, desenvolvimento sustentável significa qualificar o crescimento e reconciliar o desenvolvimento econômico com a necessidade de se preservar 0 meio ambiente (BINSWANGER, 2002, p. 42).

O relatório Hammarskjöld (1975, p. 7) corrobora com tal definição quando explica que o desenvolvimento pode ser considerado como "parte integrante, valor agregado e processo cultural, que engloba o ambiente natural, as relações sociais, educação, produção, consumo e bem-estar". Nesta linha, o desenvolvimento é interpretado como um processo de aprendizagem social, de acordo com sua capacidade de adaptação, visto que cada sociedade pode vir a redirecioná-lo mediante sua característica cultural ou natural, pois passa a ser compreendido como um todo (SACHS, 1998).

ORSIOLLI, T. A. E.; NOBRE, F. S. Estudo do empreendedorismo sob a ótica do desenvolvimento sustentável. Revista de Empreendedorismo e Gestão de Pequenas Empresas, v.4, n.3, 2015. 
Assim, o desenvolvimento sustentável se estabelece na busca por ações que permitam gerar renda econômica e ao mesmo tempo reduzam o impacto social e ambiental. Para isso, Sachs (1998) aponta que o desequilíbrio de mercado juntamente com a transformação econômica contribuem para que cada geração reconheça as preocupações relacionadas às questões ecológicas e sociais, bem como às necessidades e oportunidades de crescimento advindas dessa relação (SCHUMPETER, 1982).

Brown (1982, p. 75) sugere que para a sociedade implementar os princípios do desenvolvimento sustentável, são necessários ajustes que ocorram "[...] em resposta as forças econômicas, algumas em resposta às mudanças de políticas públicas, e outros ainda, como resultado de mudanças voluntárias em estilos de vida".

Para que ocorra esse processo de mudança, a comunidade internacional, as organizações, nações, governos e sociedade civil precisam reconhecer os problemas ambientais (aquecimento do planeta, buraco na camada de ozônio, degradação da biodiversidade) e sociais (fome, pobreza, desigualdade), procurando responder, por meio de atitudes, soluções que reduzam tais problemas (ELKINGTON, 2012).

Diante dessa perspectiva, as organizações procuram alterar ou adicionar processos que associem o bem-estar ecológico e social para contribuírem com o desenvolvimento sustentável e atentarem-se às oportunidades direcionadas à sustentabilidade (PARRISH, 2010; BARBIERI et al., 2010).

Assim, as organizações buscam incluir os conceitos e propósitos do desenvolvimento sustentável em suas políticas e práticas, passando, simultaneamente, a considerar as três dimensões que o compõem (ambiental, social e econômica), conhecidas como os três pilares da sustentabilidade ou triple bottom line (ELKINGTON, 2012; BARBERI; CAJAZEIRA, 2012).

O termo triple bottom line (TBL) foi estabelecido por John Elkington em 1997 com o propósito de debater os princípios do desenvolvimento sustentável na esfera empresarial e direcionar as empresas para uma relação consistente com seus três pilares ou triple bottom line. Destes, destacam-se: i) Profit (Pilar econômico): representa o lucro, valor econômico que gera riquezas; ii) Planet (Pilar ambiental): 
refere-se ao capital natural, ao modo como as empresas gerem seus recursos naturais; e iii) People (Pilar social): refere-se ao capital humano, à capacidade de as organizações proverem, juntamente com seus stakeholders (internos e externos), ações voltadas para diminuir o possível impacto gerado à sociedade em que se encontram inseridas.

Em decorrência de tais mudanças, as organizações passaram a se adequar a este conceito, de modo que a gestão do triple bottom line foi incorporada às estratégias da organização, representando, assim, uma visão complementar ao modelo de economia tradicional (GIMENEZ, 2012), pois passa a abranger as relações sociais e ambientais e com isso, contribuir para o desenvolvimento sustentável (ELKIGNTON, 2012).

Diante dessas perspectivas, o Quadro 1 foi desenvolvido de acordo com as três dimensões que envolvem o Desenvolvimento Sustentável (DS) organizacional, a partir das premissas cunhadas por Elkington (2004; 2012) e baseado nos critérios definidos por Sachs (2002) e Elkington (2004; 2012).

Quadro 1 - Dimensões e critérios do desenvolvimento sustentável (DS)

\begin{tabular}{|l|l|}
\hline Dimensões do DS & Critérios do DS \\
\hline Econômica & $\begin{array}{l}\text { - Desenvolvimento econômico equilibrado; } \\
\text { - Investimento em tecnologia e inovação; } \\
\text { - Capacidade de modernização contínua dos instrumentos de } \\
\text { produção. } \\
\text { - Desconsiderar fatores de produção que possam gerar } \\
\text { impactos negativos na sociedade e meio ambiente. }\end{array}$ \\
\hline \multirow{5}{*}{ Ambiental } & $\begin{array}{l}\text { - Gestão eficiente dos recursos naturais; } \\
\text { - Limitação do uso de recursos não renováveis a partir da da } \\
\text { substituição por aqueles renováveis e/ou abundantes; } \\
\text { - Redução da poluição e uso de tecnologias limpas. }\end{array}$ \\
\hline \multirow{5}{*}{ Social } & $\begin{array}{l}\text { - Alcance de um patamar razoável de homogeneidade social; } \\
\text { - Distribuição de renda justa; } \\
\text { - Emprego pleno e/ou autônomo com qualidade de vida decente; } \\
\text { - Igualdade no acesso aos recursos e serviços sociais; } \\
\text { - Estabelecer relações de confiança, a partir dos níveis de } \\
\text { igualdade de investimento no capital humano. }\end{array}$ \\
\hline
\end{tabular}

Fonte: Elaborado pelos autores com base em Elkington (2004; 2012); Sachs (1993; 2002).

A partir do quadro exposto, é possível inferir que o desenvolvimento sustentável voltado ao ambiente empresarial demanda soluções que integrem os três pilares da sustentabilidade, a fim de gerar lucro e proporcionar prudência 
ambiental e equidade social (SACHS, 2002; ELKINGTON, 2012), uma vez que as organizações passam a ser vistas como agentes participantes neste desenvolvimento (HART; MILSTEIN, 2003).

Segundo Hart e Milstein (1999), as organizações voltadas a este propósito estabelecem novos arranjos para os seus métodos convencionais de produção e buscam identificar oportunidades inovadoras que possam ser alinhadas à sua estratégia, proporcionando condições para a criação de vantagem competitiva, bem como de novas oportunidades de negócios a partir da inclusão do progresso ambiental e social nas suas pautas (SCHALTEGGER; WAGNER, 2011).

Nesse sentido, percebe-se que o fenômeno do desenvolvimento sustentável contribui para a geração de novas oportunidades e negócios que se relacionam aos seus princípios (PARRISH, 2008), de modo que sua amplitude passa a influenciar as formas de empreender, gerando novos tipos de empreendedorismo que envolvem questões econômicas, sociais e ambientais, podendo beneficiar a sociedade com novos valores (PARRISH, 2010).

Segundo Dean e McMullen (2007, p. 72), "cada tipo de empreendedorismo pode implicar diferenças substantivas entre os processos, habilidades $\mathrm{e}$ competências requeridas, riscos e resultados", permitindo que os empreendedores possam criar novas estruturas institucionais que possibilitem explorar as oportunidades sustentáveis (PACHECO; DEAN; PAYNE, 2010).

Assim, surgem o empreendedorismo social, ambiental e o sustentável. Porém, os dois primeiros abrangem parcialmente os princípios do desenvolvimento sustentável, visto que envolvem apenas algumas áreas de interesse, ao contrário do empreendedorismo sustentável, o qual busca abordar as dimensões econômica, ambiental e social em um empreendimento (TILLEY; YOUNG, 2009).

A partir dos elementos apresentados, nota-se que o movimento do desenvolvimento sustentável proporcionou a expansão de seu conceito, antes relacionado às nações e ao ambiente institucional, para abranger a sociedade civil e o ambiente organizacional a fim de gerar valor à sociedade por meio de oportunidades empreendedoras sustentáveis.

Neste momento é importante evidenciar os conceitos e critérios que norteiam o empreendedorismo sustentável. 
Relacionando critérios do empreendedorismo sustentável às dimensões do desenvolvimento sustentável

As diversas discussões desencadeadas pelo desenvolvimento sustentável incentivaram a sociedade e o meio empresarial a repensarem sobre como poderiam utilizar seus recursos para gerar valores sociais e ambientais, sobretudo para garantir o atendimento às necessidades das gerações do presente, sem comprometer as gerações do futuro.

Diante disso, o empreendedorismo sustentável passa a representar uma alternativa de disseminar o desenvolvimento sustentável por meio da adequação dos princípios ambientais, sociais e econômicos aos seus produtos e processos. No entanto, apesar da literatura abordar esse contexto, poucos estudiosos têm explorado essa relação buscando compreender como alguns desafios do desenvolvimento sustentável podem principalmente ser minimizados por meio de ações empreendedoras que envolvam as dimensões sociais, ambientais e econômicas ao mesmo tempo (HALL; DANEKE; LENOX, 2010).

O quadro 2 a seguir buscou adequar os critérios do Empreendedorismo Sustentável (ES) evidenciados pelo modelo de Young e Tilley (2006) às dimensões e critérios do Desenvolvimento Sustentável (DS). 
Quadro 2 - Critérios de desenvolvimento sustentável (DS) e empreendedorismo sustentável (ES)

\begin{tabular}{|c|c|c|}
\hline $\begin{array}{c}\text { Dimensões do } \\
\text { DS }\end{array}$ & Critérios do DS & Critérios do ES \\
\hline Econômica & $\begin{array}{l}\text { - Desenvolvimento econômico } \\
\text { equilibrado; } \\
\text { - Investimento em tecnologia e } \\
\text { inovação; } \\
\text { - Capacidade de modernização } \\
\text { contínua dos instrumentos de } \\
\text { produção. } \\
\text { - Desconsiderar fatores que } \\
\text { implicam na produção e processo } \\
\text { e possam gerar impactos a } \\
\text { sociedade e meio ambiente. }\end{array}$ & $\begin{array}{l}\text { - Busca bem-estar econômico a } \\
\text { partir de decisões e operações } \\
\text { empresariais (produtos e } \\
\text { processos); } \\
\text { - Distribuir riqueza entre as } \\
\text { gerações presentes e futuras. }\end{array}$ \\
\hline Ambiental & $\begin{array}{l}\text { - Gestão eficiente dos recursos } \\
\text { naturais; } \\
\text { - Limitação do uso de recursos } \\
\text { não renováveis a partir da } \\
\text { substituição por aqueles } \\
\text { renováveis e/ou abundantes; } \\
\text { - Redução da poluição e uso de } \\
\text { tecnologias limpas. }\end{array}$ & $\begin{array}{l}\text { - Ações que evitem a degradação } \\
\text { do ecossistema; } \\
\text { - Decisões e operações } \\
\text { ambientais empresariais. }\end{array}$ \\
\hline Social & $\begin{array}{l}\text { - Alcance de um patamar razoável } \\
\text { de homogeneidade social; } \\
\text { - Distribuição de renda justa; } \\
\text { - Emprego pleno e/ou autônomo } \\
\text { com qualidade de vida decente; } \\
\text { - Igualdade no acesso aos } \\
\text { recursos e serviços sociais; } \\
\text { - Estabelecer relações de } \\
\text { confiança, a partir dos níveis de } \\
\text { igualdade de investimento no } \\
\text { capital humano. }\end{array}$ & $\begin{array}{l}\text { - Empresas e indivíduos que a } \\
\text { compõem, possuem } \\
\text { responsabilidade sobre qualquer } \\
\text { impacto que incide sob as } \\
\text { gerações futuras; } \\
\text { - Busca bem-estar social a partir } \\
\text { das decisões e operações } \\
\text { empresariais. }\end{array}$ \\
\hline
\end{tabular}

Fonte: Elaborado pelos autores com base em Elkington (2004; 2012); Sachs (1993; 2002); Young e Tilley (2006).

De acordo com o quadro 2, é possível notar que o empreendedorismo sustentável procura operacionalizar cada dimensão do desenvolvimento por meio de suas ações para melhorar e incentivar práticas ambientais e sociais, ao mesmo tempo em que geram ganhos para os empreendedores e para a economia em si (COHEN; WINN, 2007; DEAN; MCMULLEN, 2007). Isto contribui tanto para a produção de bens e serviços, quanto para melhoria das condições sociais da população (PATZELT; SHEPHERD, 2011). 
Esta forma de empreendedorismo busca auxiliar na solução de problemas ambientais e sociais, integrando tais aspectos com a finalidade de contribuir para o desenvolvimento sustentável por meio de suas atividades empresariais. Para tanto, esses empreendedores passam a ser compreendidos como agentes que buscam ir além da transformação econômica e através de processos cognitivos mais complexos, procuram envolver constructos sociais e ambientais nas suas decisões (NOBRE; RIBEIRO, 2013).

A próxima seção apresenta o Sistema Mandalla de Produção Familiar Rural (SMPFR) a fim de ilustrar uma possível relação entre o empreendedorismo sustentável e o desenvolvimento sustentável, bem como evidenciar pressupostos teóricos que os inter-relacionam.

\section{Sistema Mandalla de produção familiar rural (SMPFR)}

Evoluções tecnológicas e transformações sociais ocorridas nas últimas décadas geraram impactos significativos na economia e influenciaram o avanço de atividades realizadas por empresas agropecuárias e de agricultura familiar no cenário brasileiro (SILVA et al., 2012; IBGE, 2006).

Diante deste contexto, a agricultura familiar destaca-se como exemplo de sobrevivência deste processo de modernização, uma vez que possui a capacidade de gerar renda e ocupações dentro dos limites rurais, à medida que integra o processo produtivo ao trabalho familiar. Com isso, contribui para gerar o desenvolvimento econômico a partir da descentralização da renda e redução das desigualdades sociais (CARNEIRO, 1997; COSTA et al., 2014).

Costa et al. (2014, p. 14) ainda comprovam tais evidências quando argumentam que a "agricultura familiar é responsável por garantir boa parte da segurança alimentar do país". Explicam que o Instituto Brasileiro de Geografia e Estatística (IBGE), no censo agropecuário do ano de 2006, apontou que a produção familiar rural representa cerca de $84,4 \%$ das propriedades rurais e, por conseguinte, $38 \%$ do valor da produção agropecuária brasileira. 
Essa realidade pode ser mais facilmente percebida na região semiárida nordestina, a qual abrange municípios localizados nos estados de Alagoas, Bahia, Ceará, Paraíba, Pernambuco, Piauí, Rio Grande do Norte e Sergipe (BRASIL, 2005). Devido ao seu contexto social, histórico e geográfico, busca-se na agricultura familiar nesta região, uma alternativa para implantar o agronegócio, bem como apoiar o desenvolvimento local de acordo com os aspectos econômicos, sociais, ecológicos e culturais (COSTA et al., 2014).

Nesse sentido, é primordial a utilização de tecnologias adequadas ou apropriadas - TA (ajustadas ou adaptadas a algum propósito ou uso específico) para aprimorar o manejo sustentável dos recursos voltados à agricultura familiar e possibilitar mudanças no sistema de produção agropecuária do semiárido nordestino (RODRIGUES; BARBIERI, 2008; KÜSTER; MARTÍ, 2006). Para tanto, são criadas tecnologias de geração de energia a partir da biomassa com a finalidade de proporcionar sistemas de baixo custo para a produção rural.

Outra forma de tecnologia, a social, considerada como aquela que "compreende produtos, técnicas ou metodologias replicáveis, desenvolvidas na interação com a comunidade e que representem efetivas soluções de transformação social" (RODRIGUES; BARBIERI, 2008, p. 1070), também contribui para o processo produtivo desta forma de agricultura. Como exemplo, pode-se destacar o Sistema Mandalla de Produção Familiar Rural, denominado nesse trabalho por SMPFR (KÜSTER; MARTÍ, 2006).

Reina et al. (2010) compreendem o SMPFR como um consórcio de produção agrícola voltado para pequenas comunidades rurais, cuja finalidade consiste em variar as atividades agrícolas por meio da adição de tecnologia adequada, para melhorar a produção de alimentos de maneira sustentável incialmente em regiões semiáridas e, por consequência, aumentar a renda das famílias produtoras.

Por sua vez, Labad e Rodrigues (2006) argumentam que o SMPFR é considerado uma tecnologia social de baixo custo operacional que gere a produção agrícola a partir de um método participativo de planejamento por meio de instrução de hortas circulares e irrigação de terra. 
Este sistema rural procura proporcionar incentivos para fortalecer e aumentar a produtividade familiar rural, de modo a promover a reestruturação econômica, social e ambiental das comunidades em seus municípios e regiões (KÜSTER; MARTÍ, 2006; LABAD; RODRIGUES, 2006). O projeto foi idealizado por Willy Pessoa Rodrigues, no ano de 2002, em parceria com um grupo de jovens universitários. Ele criou a agência Mandalla DHSA (Desenvolvimento Holístico Sistêmico Ambiental), uma Organização da Sociedade Civil de Interesse Público (OSCIP), com a finalidade de viabilizar a produção sustentável de alimentos em regiões semiáridas e contribuir para gerar renda e sustento para os pequenos agricultores (MARTINS et al., 2012; LABAD; RODRIGUES, 2006).

Alguns autores se referem à Mandalla como sistema e outros como projeto. Contudo, neste artigo, ambas as denominações serão consideradas sinônimas. Desta forma, pode-se inferir que o SMPFR é um método de produção baseado na filosofia indiana, o qual é caracterizado por forma circular e concêntrica de canteiros que se encontram ao redor de uma fonte de água, interligados por um sistema de irrigação comunitária (MARTINS et al., 2012; KÜSTER; MARTÍ, 2006).

Este projeto de baixo custo reproduz a estrutura do sistema solar, visto que é composto por nove círculos que se encontram ao redor de um reservatório de água localizado no centro que, além de fornecer água, é utilizado para a criação de peixes, patos e marrecos (REINA et al., 2010). Tal processo inicia-se a partir da produção do primeiro círculo, para assim, dar continuidade aos demais, até chegar ao último (MARTINS et al., 2012).

Os círculos possuem função determinada à medida que os três primeiros, denominados "Círculo de Melhoria da Qualidade de Vida Ambiental" buscam atender as necessidades de subsistência da família a partir do cultivo de hortaliças e plantas medicinais. Os cinco círculos subsequentes, destinam-se à agricultura diversa, tal como milho, feijão verde, abóboras e frutas, voltado para uma produção em maior escala, a fim de aumentar a comercialização e gerar renda para o agricultor, representando assim, os "Círculos da Produtividade Econômica". O "Círculo do Equilíbrio Ambiental" é o último que compõe a Mandalla, pois se destina a proteger o sistema com o auxílio de cercas vivas e quebra-ventos para prover os nutrientes 
necessários à recuperação do solo, bem como melhorar a produtividade (REINA et al., 2010). O SMPFR é ilustrado na figura 2 a seguir.

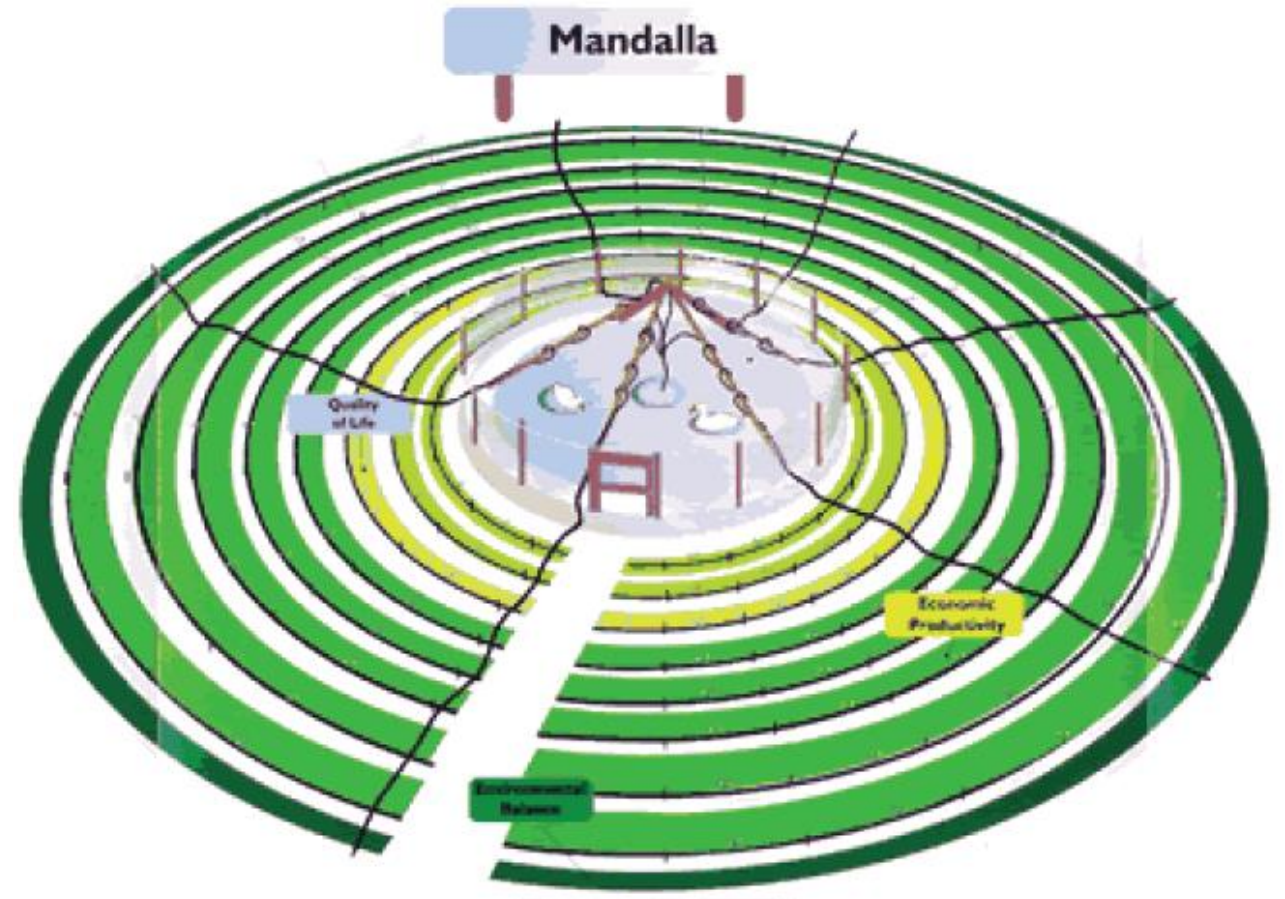

Figura 2 - Sistema Mandalla

Fonte: Labad e Rodrigues (2006, p.179).

Com o objetivo de gerar o desenvolvimento das comunidades, proporcionar renda e sustento aos agricultores, e corresponder às dimensões sustentáveis, a Agência Mandalla DHSA se baseou nos princípios da permacultura que consiste em um sistema de planejamento que busca envolver elementos éticos, socioeconômicos e ambientais, a fim de gerar ambientes humanos sustentáveis. Esta técnica ambiental possibilita ao agricultor utilizar a terra e a água sem desperdícios ou poluição, e consumo mínimo de energia, apropriando-se de métodos alternativos (energia solar, bomba d'água com o auxílio de material reciclado ou inutilizado, pedal giratório movido à força física, entre outros), com o propósito de tornar esse processo dinâmico e contínuo entre os agricultores (LABAD; RODRIGUES, 2006).

Nota-se, portanto, que o SMPFR surge como uma estrutura de produção agrícola de baixo custo e fácil replicação, voltada para fortalecer e aprimorar a agricultura familiar de maneira sustentável, a partir do desenvolvimento harmonioso de seus habitantes, a fim de gerar emprego e renda em comunidades rurais, bem 
como influenciar nos resultados econômicos, sociais e ambientais do meio rural, município e região como um todo (COSTA et al., 2013; MARTINS et al., 2012; LABAD; RODRIGUES, 2006).

Nesta abordagem, o SMPFR atende alguns elementos fundamentais de modelos de negócio voltados à Base da Pirâmide (PRAHALAD, 2006), entre eles, a inclusão de famílias rurais na função de microprodutores, microinovadores, microempreendedores, microconsumidores e microinvestidores.

\section{Discussão}

O movimento para o desenvolvimento sustentável tem proporcionado à sociedade e aos seus agentes uma ampla reflexão relacionada à degradação ambiental e aos problemas sociais (BARBIERI, 2006; SACHS, 2007; SCOTTO; CARVALHO; GUIMARÃES, 2008). Resultados e indicadores de relatórios da Organização das Nações Unidas (UNEP, 2012) têm pressionado nações, governos, sociedade civil e organizações, a repensarem de maneira mais profunda os seus valores e atitudes a fim de criarem transformações nas suas estratégias e decisões que estejam alinhadas aos preceitos do desenvolvimento sustentável.

Essas mudanças têm possibilitado às organizações adequarem objetivos sociais e ambientais aos seus métodos de gestão e produção (ALIGLERI; ALIGRERI; KRUGLIANSKAS, 2009). Influenciaram também, o surgimento de oportunidades empreendedoras como meio de fomentar a transformação de produtos e processos de maneira sustentável (HALL; DANEKE; LENOX, 2010).

Diante disso, o empreendedorismo sustentável surge como forma de integrar as dimensões do desenvolvimento sustentável ao ambiente e práticas organizacionais, para que assim, possam agregar os ganhos econômicos a ações ambientais e sociais que atribuam benefícios aos indivíduos, à economia e à sociedade (COHEN; WINN, 2007; SHEPHERD; PATZELT, 2011).

A partir da inter-relação entre os critérios do empreendedorismo sustentável e as dimensões do desenvolvimento sustentável dispostos no quadro 2, percebe-se que esta forma de empreendedorismo direciona suas estratégias a fim de gerar 
valores sociais e ambientais, de modo que suas ações constituem em agregar tais valores aos processos e/ou produtos empresariais (SCHALTEGGER; WAGNER 2011).

Esta inter-relação e contribuição podem ser verificadas através do exemplo do SMPFR, uma vez que este sistema proporciona a inclusão de pessoas e famílias de baixa renda em um processo de criação de valor socioeconômico que as transforma em novos microprodutores, microinovadores, microempreendedores, microconsumidores e microinvestidores. Esta transformação envolve o desenvolvimento local por meio de processos e ações de baixo custo, replicáveis, ao mesmo tempo em que busca integrar os valores sociais e ambientais à geração de renda. Esses aspectos são apresentados no Quadro 3. 
Quadro 3 - Critérios de desenvolvimento sustentável (DS), empreendedorismo sustentável (ES) e características do SMPFR

\begin{tabular}{|c|c|c|c|}
\hline $\begin{array}{l}\text { Dimensões } \\
\text { do DS }\end{array}$ & Critérios do DS & Critérios do ES & SMPFR \\
\hline Econômica & $\begin{array}{l}\text { - Desenvolvimento } \\
\text { econômico equilibrado; } \\
-\quad \text { Investimento em } \\
\text { tecnologia e inovação; } \\
\text { - Capacidade de } \\
\text { modernização contínua } \\
\text { dos instrumentos de } \\
\text { produção. } \\
\text { - Desconsiderar fatores } \\
\text { que implicam na produção } \\
\text { e processo e possam } \\
\text { gerar impactos a } \\
\text { sociedade e meio } \\
\text { ambiente. }\end{array}$ & $\begin{array}{l}\text { - Busca bem-estar } \\
\text { econômico a partir de } \\
\text { decisões e operações } \\
\text { empresariais (produtos e } \\
\text { processos); } \\
\text { - Distribuir riqueza entre } \\
\text { as gerações presentes e } \\
\text { futuras. }\end{array}$ & $\begin{array}{l}\text { - Produção agrícola de } \\
\text { baixo custo e fácil } \\
\text { replicação; } \\
\text { - Acesso ao } \\
\text { microcrédito; } \\
\text { - Gera emprego e renda } \\
\text { aos produtores rurais; } \\
\text { - Introdução de novas } \\
\text { tecnologias; }\end{array}$ \\
\hline Ambiental & $\begin{array}{l}\text { - Gestão eficiente dos } \\
\text { recursos naturais; } \\
\text { - Limitação do uso de } \\
\text { recursos não renováveis a } \\
\text { partir da substituição por } \\
\text { aqueles renováveis e/ou } \\
\text { abundantes; } \\
\text { - Redução da poluição e } \\
\text { uso de tecnologias } \\
\text { limpas. }\end{array}$ & $\begin{array}{l}\text { - Ações que evitem a } \\
\text { degradação } \\
\text { ecossistema; } \\
\text { - Decisões e operações } \\
\text { ambientais empresariais. }\end{array}$ & 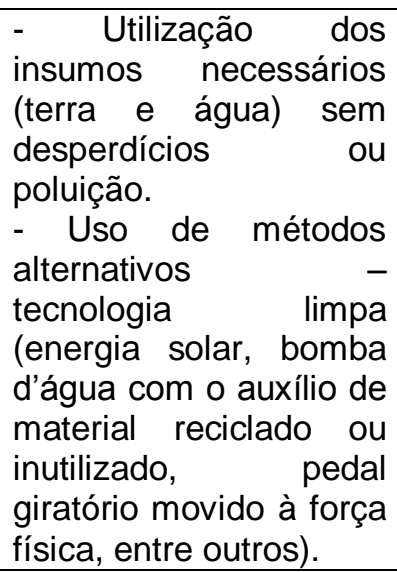 \\
\hline Social & $\begin{array}{l}\text { - Alcance de um patamar } \\
\text { razoável de } \\
\text { homogeneidade social; } \\
\text { - Distribuição de renda } \\
\text { justa; } \\
\text { - Emprego pleno e/ou } \\
\text { autônomo com qualidade } \\
\text { de vida decente; } \\
\text { - Igualdade no acesso aos } \\
\text { recursos e serviços } \\
\text { sociais; } \\
\text { - Estabelecer relações de } \\
\text { confiança, a partir dos } \\
\text { níveis de igualdade de } \\
\text { investimento no capital } \\
\text { humano. }\end{array}$ & $\begin{array}{l}\text { - Empresas e indivíduos } \\
\text { que a compõem, } \\
\text { possuem } \\
\text { responsabilidade sobre } \\
\text { qualquer impacto que } \\
\text { incide sob as gerações } \\
\text { futuras; } \\
\text { - Busca bem-estar social } \\
\text { a partir das decisões e } \\
\text { operações empresariais. }\end{array}$ & $\begin{array}{l}\text { - Busca por meio de } \\
\text { ações produtivas, } \\
\text { melhorar a qualidade } \\
\text { de vida dos indivíduos, } \\
\text { famílias e comunidade } \\
\text { envolvida; }\end{array}$ \\
\hline
\end{tabular}

Fonte: Elaborado pelos autores com base em Elkington (2004; 2012); Labad e Rodrigues (2006); Maia (2006); Sachs (2002); Young e Tilley (2006). 
A partir do Quadro 3, é possível verificar que algumas ações que permeiam - SMPFR podem estar inter-relacionadas aos critérios do empreendedorismo sustentável, sendo possível compreender que esta forma de empreendedorismo pode contribuir para um desenvolvimento sustentável. Isso pode ser evidenciado por meio de ações empresariais ou, neste caso, ações produtivas que podem: melhorar a qualidade de vida dos indivíduos, famílias e comunidade envolvida; proporcionar técnicas que evitem desperdício de recursos e degradação do meio ambiente; auxiliar na renda familiar; introduzir novas tecnologias e inovação; entre outros (COSTA et al., 2013; LABAD; RODRIGUES, 2006).

Assim, de acordo com esta associação entre o SMPFR e 0 empreendedorismo sustentável, pode-se dizer que o SMPFR contribui para o desenvolvimento sustentável à medida que procura corresponder aos princípios sociais, ambientais e econômicos, de maneira contínua, a fim de propagar estes três elementos por meio de suas estratégias de negócios, bem como gerar valores às comunidades envolvidas.

O SMPFR pode ser compreendido como uma forma ou caso de empreendedorismo sustentável, voltado principalmente para uma produção agrícola familiar de baixa escala que quando replicada em outras comunidades, pode se tornar uma produção agrícola em maior escala, levando em consideração o respeito ao meio ambiente e seus recursos naturais (MAIA, 2006).

A associação entre o SMPFR e o empreendedorismo sustentável se torna evidente a partir da observação de que o SMPFR busca proporcionar ao agricultor, técnicas alternativas de manejo que intensifiquem a agricultura familiar por meio da utilização dos insumos necessários (terra e água) sem desperdícios ou poluição. Tais atitudes possibilitam criar e manter estas condições ao mesmo tempo em que procuram favorecer o desenvolvimento socioeconômico, gerando emprego e renda aos produtores rurais (LABAD; RODRIGUES, 2006; COSTA et al., 2013). 


\section{Considerações finais}

O presente estudo teve como objetivo, levantar os critérios do empreendedorismo sustentável e associá-los às dimensões do desenvolvimento sustentável. Por conseguinte, contribuiu-se para uma melhor compreensão sobre como o empreendedorismo corrobora para um desenvolvimento que envolva dimensões econômica, social e ambiental.

De acordo com a revisão bibliográfica apresentada neste trabalho, percebese que o movimento para 0 desenvolvimento sustentável tem mobilizado organizações a repensarem suas formas de gestão e produção. Isto para satisfazerem uma nova gama de perspectivas de stakeholders e da sociedade, alinhadas a preceitos que vão além de fronteiras econômicas e que incluem valores socioambientais. É importante também estarem atentas às exigências ambientais e sociais impostas através de normas legais, sejam elas locais, regionais ou mesmo globais (ALIGLERI; ALIGRERI; KRUGLIANSKAS, 2009).

Assim, as organizações passam a ser compreendidas como agentes que procuram abranger objetivos que vão além do ideal econômico (NOBRE; RIBEIRO, 2013) e passam a melhorar seus métodos de gestão e produção, bem como reconhecerem oportunidades empreendedoras que incorporem os aspectos sociais e ambientais em suas atividades.

Ressalta-se que o empreendedorismo sustentável não é analisado por uma ótica idealista, mas por elementos concretos, situacionais (micro), existentes em um contexto local, excluindo-se para tanto, perspectivas de cunho generalista no trato com as discussões socioambientais. Diante disso, é possível perceber que o empreendedorismo sustentável se destaca com a finalidade de unir as oportunidades relacionadas ao ambiente natural e social, a fim de criar bens e serviços que sustentem tanto o ambiente ecológico quanto o ambiente comum e com isso, proporcione ações que contribuam para o desenvolvimento do próprio empreendimento e da sociedade em geral (PATZELT; SHEPHERD, 2011).

Desta forma, constata-se que existem distintas estratégias de sustentabilidade que contribuem para um desenvolvimento sustentável (NOBRE; 
RIBEIRO, 2013; NOBRE; WALKER; HARRIS, 2012). Contudo, embora algumas relações entre estratégias de sustentabilidade e dimensões do desenvolvimento sustentável sejam aparentemente tautológicas, destacou-se a importância de descrever como essas relações estão associadas ou se formam, e compreender quais estratégias estão associadas a cada uma das dimensões, como verificado a partir do exemplo do SMPFR.

Nota-se, portanto, que o empreendedorismo sustentável pode ser considerado um agente que pode contribuir para o desenvolvimento sustentável à medida que procura integrar e propagar os princípios sociais, ambientais e econômicos de maneira conjunta por meio de suas estratégias de negócios, bem como gerar valores às comunidades envolvidas.

Como extensão do presente trabalho, é possível sugerir estudos capazes de promover estudo aprofundado, ou mesmo validação teórica e empírica de um modelo de classificação de empreendimentos em uma escala de "não sustentáveis e parcialmente sustentáveis a sustentáveis", podendo ser agrupados da seguinte maneira: Grupo 1: empreendimentos que não satisfazem critérios do empreendedorismo sustentável; Grupo 2: empreendimentos que satisfazem parcialmente critérios do empreendedorismo sustentável; e Grupo 3: empreendimentos que satisfazem critérios do empreendedorismo sustentável.

Por fim, sugere-se a realização de estudos de casos múltiplos ou levantamentos (surveys) a fim de melhor compreender como se dá o processo de desenvolvimento sustentável a partir de práticas de empreendedorismo sustentável, bem como para que seja possível encontrar padrões e estabelecer proposições sobre a relação dos construtos estudados.

\section{Referências:}

ABRAHAMSSON, A. Sustainopreneurship - business with a cause: Conceptualizing entrepreneurship for sustainability. Master Thesis (Business Administration) - School of Management and Economics, Växjö University, Sweden, 2007.

ALIGLERI, L.; ALIGRERI, L. A; KRUGLIANSKAS, I. Gestão socioambiental: responsabilidade e sustentabilidade do negócio. São Paulo: Atlas, 2009.

ORSIOLLI, T. A. E.; NOBRE, F. S. Estudo do empreendedorismo sob a ótica do desenvolvimento sustentável. Revista de Empreendedorismo e Gestão de Pequenas Empresas, v.4, n.3, 2015. 
BARBIERI, J. C. et al. Inovação e sustentabilidade: novos modelos e proposições. RAE - Revista de Administração e Economia, v. 50, n. 2, p. 146 - 154, 2010.

BARBIERI, J. C. O local e o global na implementação do desenvolvimento sustentável. In: CABRAL, A.; COELHO, L. (orgs.). Mundo em transformação caminhos para o desenvolvimento sustentável. Belo Horizonte: Autêntica, 2006.

BARBIERI, J. C.; CAJAZEIRA, J. E. R. Responsabilidade Social Empresarial e empresa sustentável: da teoria à prática. 2. ed. São Paulo: Saraiva, 2012.

BINSWANGER, H. C. Fazendo a Sustentabilidade Funcionar. In: CAVALCANTI, C. (Org.). Meio ambiente, desenvolvimento sustentável e políticas públicas. São Paulo: Cortez, 2002.

BOSZCZOWSKI, A. K.; TEIXEIRA, R. O empreendedorismo sustentável e o processo empreendedor: em busca de oportunidades de novos negócios como solução para problemas ambientais e sociais. Revista Economia \& Gestão, v. 12, n. 29, p. $141-168,2012$.

BRASIL. Ministério da Integração Nacional. Nova delimitação do semiárido brasileiro. Brasília, 2005.

CARNEIRO, M. J. Política pública e agricultura familiar: uma leitura do Pronaf. Estudos Sociedade e Agricultura, v. 8, n. 4, p. 70 - 82, 1997.

CERVO, A. L.; BERVIAN, P. A. Metodologia Cientifica. 5. ed. São Paulo: Prentice Hall, 2002.

CHOI, D. Y.; GRAY, E. R. The venture development processes of "sustainable" entrepreneurs. Management Research News, v. 31, n. 8, p. 558 - 569, 2008.

COHEN, B.; WINN, M. I. Market Imperfections, oportunity and sustainable entrepreneurship. Journal of Business Venturing, v. 22, p. 29 - 49, 2007.

COLLIS, J.; HUSSEY, R. Pesquisa em Administração: um guia prático para alunos de graduação e pós-graduação. 2. ed. Porto Alegre: Bookman, 2005.

COMISSÃO MUNDIAL SOBRE MEIO AMBIENTE E DESENVOLVIMENTO (CMMAD). Nosso Futuro Comum. 2. ed. Rio de Janeiro: FGV, 1991.

ORSIOLLI, T. A. E.; NOBRE, F. S. Estudo do empreendedorismo sob a ótica do desenvolvimento sustentável. Revista de Empreendedorismo e Gestão de Pequenas Empresas, v.4, n.3, 2015. 
COSTA, S. J. et al .Inovação Social, Prazer e Sofrimento no Trabalho: o Caso do Projeto Mandalla no Ceará. Administração Pública e Gestão Social, v. 6, n. 1, p. $11-18,2014$.

COSTA, S. J. et al. Social Technology as a Sustainable Public Policy: The Mandalla Project in Ceará. Journal of Technology Management \& Innovation, v. 8, p. 177 187, 2013.

DEAN; T. J.; MCMULLEN, J. S. Toward a theory of sustainable entrepreneurship: reducing environmental degradation through entrepreneurial action. Journal of Business Venturing, v. 22, n. 1, p. 50 - 76, 2007.

DEZIN, N. K.; LINCOLN, Y. S. O planejamento da pesquisa qualitativa: teorias e abordagens. 2. ed. Porto Alegre: Artmed, 2006.

DYLLICK ,T.; HOCKERTS, K. Beyond the business case for corporate sustainability. Business Strategy and the Environment, v. 11, n. 2, p. 130 - 141, 2002.

ELKINGTON, J. Enter the triple bottom line. In: HENRIQUES, A.; RICHARDSON, J (Orgs.) The triple bottom line, does it all add up?. London: Earthscan, 2004.

ELKINGTON, J. Sustentabilidade: canibais com garfo e faca. São Paulo: M. Books, 2012.

FLICK, U. Uma introdução à pesquisa qualitativa. 2. ed. Porto Alegre: Bookman, 2004.

GIMENEZ, A. P. A sustentabilidade e a inovação como um desafio para a gestão das organizações. $47 \mathrm{f}$. Tese - (Processo seletivo de Docente da UFPR). Departamento de Ciências Sociais Aplicadas. Universidade Federal do Paraná, Curitiba, 2012.

HALL, J. K.; DANEKE, G. A.; LENOX, M. J. Sustainable development and entrepreneurship: Past contributions and future directions. Journal of Business Venturing, v. 25, p. $439-448,2010$.

HALL, J. K.; DANEKE, G. A.; LENOX, M. J. Sustainable development and entrepreneurship: Past contributions and future directions. Journal of Business Venturing, v. 25, p. $439-448,2010$.

HAMMARSKJÖLD. What Now: the 1975 Dag Hammarskjöld Report. New York: United Nations General Assembly, 1975.

ORSIOLLI, T. A. E.; NOBRE, F. S. Estudo do empreendedorismo sob a ótica do desenvolvimento sustentável. Revista de Empreendedorismo e Gestão de Pequenas Empresas, v.4, n.3, 2015. 
HART, S. L.; MILSTEIN, M. B. Global sustainability and the creative destruction of industries. Sloan Management Review, v. 41, n.1, p. 23 - 33, 1999.

HOCKERTS, K.; WÜSTENHAGEN, R. Greening Goliaths versus emerging Davids Theorizing about the role of incumbents and new entrants in sustainable entrepreneurship. Journal of Business Venturing, v. 25, n. 5, p. 481 - 492, 2010.

KÜSTER, A.; MARTÍ, J. F. Tecnologias para o semiárido nordestino. In.: KÜSTER, A.; MARTÍ, J. F.; MELCHERS, I. (Orgs.) Tecnologias apropriadas para terras secas: manejo sustentável de recursos naturais em regiões semi-áridas no nordeste do Brasil. Fortaleza: Fundação Konrad Adenauer, 2006.

LABAD, F.; RODRIGUES, N. Círculos de prosperidade Projeto Mandalla - DHSA. In: KÜSTER, A.; MARTÍ, J. F.; MELCHERS, I. (Orgs.) Tecnologias apropriadas para terras secas: manejo sustentável de recursos naturais em regiões semi-áridas no nordeste do Brasil. Fortaleza: Fundação Konrad Adenauer, 2006.

MAIA, G. N. Manejo sustentável da Caatinga. In: KÜSTER, A.; MARTÍ, J. F.; MELCHERS, I. (Orgs.) Tecnologias apropriadas para terras secas: manejo sustentável de recursos naturais em regiões semi-áridas no nordeste do Brasil. Fortaleza: Fundação Konrad Adenauer, 2006.

MAJID, I. A.; KOE, W-L. Sustainable Entrepreneurship (SE): A Revised Model Based on Triple Bottom Line (TBL). International Journal of Academic Research in Business and Social Sciences, v. 2, n. 6, p. 293 - 310, 2012.

MARTINS, G. A.; THEÓPHILO, C. R. Metodologia de investigação científica para ciências sociais aplicadas. São Paulo: Atlas, 2007.

MARTINS, R. K. et al. O Sistema Mandala de Produção de Alimentos: uma estratégia para 0 desenvolvimento da agricultura familiar. In: ENCONTRO NACIONAL DE GEOGRAFIA AGRÁRIA. 2012, Universidade Federal de Uberlândia. Anais... Uberlândia: UFU, 2012.

NOBRE, F.S.; RIBEIRO, R. E. M. Cognição e Sustentabilidade: Estudo de Casos Múltiplos no Índice de Sustentabilidade Empresarial da BM\&FBovespa. Revista de Administração Contemporânea, v. 17, n. 4, p. 499 - 517, 2013.

NOBRE, F.S.; WALKER, D.; HARRIS, R. Technological, Managerial and Organizational Core Competencies: Dynamic Innovation and Sustainable Development. New York: IGI Global, 2012.

ORSIOLLI, T. A. E.; NOBRE, F. S. Estudo do empreendedorismo sob a ótica do desenvolvimento sustentável. Revista de Empreendedorismo e Gestão de Pequenas Empresas, v.4, n.3, 2015. 
O'NEILL JR, G. D.; HERSHAUER, J. C.; GOLDEN, J. S. The cultural context of sustainability entrepreneurship. Greener Management International, v. 55, p. 3346, 2009.

PACHECO, D. F.; DEAN, T. J.; PAYNE, D. S. Escaping the green prison: Entrepreneurship and the creation of opportunities for sustainable development. Journal of Business Venturing, v. 25, n. 5, p. 464 - 480, 2010.

PARRISH, B. D. Sustainability-Driven Entrepreneurship: A Literature Review. Leeds, UK: UNiversity of Leeds, 2008.

PARRISH, B. D. Sustainability-driven entrepreneurship: Principles of organization design. Journal of Business Venturing, v. 25, n. 5, p. 510-523, 2010.

PATZELT, H.; SHEPHERD, D. A. Recognizing opportunities for sustainable development. Entrepreneurship Theory \& Practice, v. 35, n. 4, p. 631 - 652, 2011.

PRAHALAD, C. K. The fortune at the bottom of the pyramid: eradicating poverty throught profits. New Jersey: Pearson Education, 2006.

RAUFFLET, E.; BRES, L.; FILION, L. J. Desenvolvimento sustentável e empreendedorismo. Revista de Empreendedorismo e Gestão de Pequenas Empresas, v. 3, n. 1, p.3 - 32, 2014.

REINA, E. et al. Tecnologia apropriada: instrumento de desenvolvimento da agricultura familiar e de comunidades rurais. In: ABREU, Y. V.; OLIVEIRA, M. A. G.; GUERRA, S. M. G. (orgs). Energia, Economia, Rotas Tecnológicas: Textos selecionados. Málaga. Espanha: Eumed.Net, Universidade de Málaga, 2010.

RODRIGUES, I.; BARBIERI, J. C. A emergência da tecnologia social: revisitando o movimento da tecnologia apropriada como estratégia de desenvolvimento sustentável. Revista de Administração Pública, v. 42, n. 6, p. 1069 - 1094, 2008.

SACHS, I. Ambiente e estilos de desenvolvimento. In: VIEIRA, P. F. (org.). Rumo à ecossocioeconomia: teoria e prática do desenvolvimento. São Paulo: Cortez, 2007.

SACHS, I. Caminhos para o desenvolvimento sustentável. 4. ed. Rio de Janeiro: Garamond, 2002.

SACHS, I. Desenvolvimento: includente, sustentável, sustentado. Rio de Janeiro: Garamond, 2008.

ORSIOLLI, T. A. E.; NOBRE, F. S. Estudo do empreendedorismo sob a ótica do desenvolvimento sustentável. Revista de Empreendedorismo e Gestão de Pequenas Empresas, v.4, n.3, 2015. 
SACHS, I. Estratégia de transição para o século XXI: desenvolvimento e meio ambiente. Tradução Magda Lopes. São Paulo: Studio Nobel: Fundação do desenvolvimento administrativo, 1993.

SACHS, I. O desenvolvimento enquanto apropriação dos direitos humanos. Estudos Avançados, v. 33, n.12, p. 149 - 156, 1998.

SCHALTEGGER, S.; WAGNER, M. Sustainable Entrepreneurship and Sustainability Innovation: Categories and Interactions. Business Strategy and the Environment, v. 20 , p. $222-237,2011$.

SCHLANGE, L. Stakeholder identification in sustainability entrepreneurship. Greener Management International, v. 55, p. 13 - 32, 2009.

SCHLANGE, L. What drives sustainable entrepreneurs? In.: APPLIED BUSINESS AND ENTREPRENEURSHIP ASSOCIATION INTERNATIONAL, 2006, Suíça. Anais... Suíça: University of Applied Sciences Chur, 2006. p. 1 - 11.

SCHUMPETER, J. A teoria do desenvolvimento econômico. São Paulo: Abril Cultural, 1982.

SCOTTO, G.; CARVALHO, I. C. M; GUIMARÃES, L. B. Desenvolvimento Sustentável. 3. ed. Petrópolis: Vozes, 2008.

SHEPHERD, D. A.; PATZELT, H. The new field of sustainable entrepreneurship: studying entrepreneurial action linking "what is to be sustained" with "what is to be developed". Entrepreneurship Theory \& Practice, v. 35, n. 1, p. 137 - 163, 2011.

SILVA, C. L. da et al. Inovação e Sustentabilidade. Curitiba: Aymará Educação, 2012.

THOMPSON, N.; KIEFER, K.; YORK, J. G. Distinctions not Dichotomies: Exploring Social, Sustainable, and Environmental Entrepreneurship. In: LUMPKIN, G. T.; KATZ, J. A. (Orgs.). Social and Sustainable Entrepreneurship - Advances in Entrepreneurship, Firm Emergence and Growth. v. 13. Bingley: Emerald Group Publishing Limited, 2011, p. 201 - 229.

TILLEY, F.; YOUNG, W. Sustainability Entrepreneurs: Could they be the True Wealth Generator of the Future? Greener Management International, v. 55, p. 79 - 92, 2009.

ORSIOLLI, T. A. E.; NOBRE, F. S. Estudo do empreendedorismo sob a ótica do desenvolvimento sustentável. Revista de Empreendedorismo e Gestão de Pequenas Empresas, v.4, n.3, 2015. 
UNITED NATIONS ENVIRONMENT PROGRAMME (UNEP) GEO5 - Global Environment Outlook: Environment for the future we want. Malta: Progress Press Ltd., 2012.

VEIGA, J. E. Desenvolvimento sustentável: o desafio do século XXI. Rio de Janeiro: Garamond, 2005.

YOUNG, W.; TILLEY, F. Can Businesses Move Beyond Efficiency? The Shift toward Effectiveness and Equity in the Corporate Sustainability Debate. Business Strategy and the Environment, v. 15, n. 6, p. 402 - 415, 2006. 